\section{Comment on: Laryngeal mask airway for general anesthesia in interventional neuroradiology procedures}

\section{To the Editor}

I have read with interest the article Laryngeal mask airway for general anesthesia in interventional neuroradiology procedures. The objective of the study was to evaluate whether using laryngeal mask airway made a difference in terms of airway security, hemodynamic changes, complications, and recovery times compared to tracheal intubation during the procedure in patients undergoing general anesthesia for endovascular treatments of unruptured cerebrovascular aneurysms. ${ }^{1}$

If we go into the details of the article, the authors mainly concentrated on the hemodynamic changes pre and post intervention, which was his conclusion, rather than airway security. Therefore, this consider relatively misleading.

\section{Correspondence}

Second, they did not comment in the intention to treat analysis. In addition, no sample size calculated for the significant conclusion.

Lastly, they did not mention the total numbers of patient screened before enrolment, this is important for the applicability of the study in majority or minority only.

\section{Abdulaziz Alshaer \\ Department of Anesthesia \\ King Fahad Military Medical Complex Dhahran, Kingdom of Saudi Arabia}

\section{Reply from the Author}

No reply was received from the Author.

\section{References}

1. Özhan MO, Eşkin MB, Atik B, Süzer MA, Çaparlar CO. Laryngeal mask airway for general anesthesia in interventional neuroradiology procedures. Saudi Med J 2019; 40: 463-468.

\title{
Supplements
}

* Supplements will be considered for work including proceedings of conferences or subject matter covering an important topic

* Material can be in the form of original work or abstracts.

* Material in supplements will be for the purpose of teaching rather than research.

* The Guest Editor will ensure that the financial cost of production of the supplement is covered.

* Supplements will be distributed with the regular issue of the journal but further copies can be ordered upon request.

* Material will be made available on Saudi Medical Journal website 